\title{
Ovarian androstenedione production is enhanced by insulin during the period of delayed ovulation in a vespertilionid bat, Scotophilus heathi
}

\author{
J. Doval and A. Krishna* \\ Department of Zoology, Banaras Hindu University, Varanasi - 221 005, India
}

\begin{abstract}
The aim of the present study was to evaluate the role of insulin in the production of high concentrations of androstenedione in the ovary of Scotophilus heathi during the period of delayed ovulation. The concentrations of serum insulin were found to be high during November and December and declined significantly before ovulation. A significant correlation was observed between circulating insulin concentration and body weight as well as with serum androstenedione concentrations. Autoradiographic study demonstrated specific accumulation of ${ }^{125}$ I-labelled insulin in the ovarian thecal and interstitial cells. Insulin increased both basal and hCG-stimulated androstenedione production by the ovary in vitro during November. These results indicate that insulin may be involved in inducing high androstenedione synthesis by the ovary and thus may be indirectly responsible for inducing delayed ovulation in S. heathi.
\end{abstract}

\section{Introduction}

The temperate zone vespertilionid bats exhibit delayed ovulation where final maturation and ovulation of Graafian follicles are postponed for several months (Oxberry, 1979). Previous studies have demonstrated that $S$. heathi, a tropical/subtropical vespertilionid bat, also exhibits this phenomenon (Krishna and Singh, 1992). Abhilasha and Krishna (1996) reported an abnormally high circulating androstenedione concentration during the period of delayed ovulation in S. heathi, which may be responsible for suppressing follicular development and ovulation. What causes this increased androstenedione production by the ovary during the period of ovulatory delay is not known. Recent studies on S. heathi demonstrated a close relationship between high androstenedione concentration and the extensive development of luteinized stromal cells (hyperthecosis) and increase in body weight due to the accumulation of adipose tissue (obesity) (Abhilasha and Krishna, 1997). A similar association between hyperandrogenism, obesity and chronic anovulation also occurs in women with polycystic ovarian syndrome (PCOS). There is some evidence to suggest that in PCOS hyperandrogenism can result from hyperinsulinaemia (Nestler and Jakubowicz, 1996; Utiger, 1996). Insulin has been shown to stimulate ovarian androgen production in vitro (Bergh et al., 1993). In rats and humans, insulin-like growth factor I (IGF-I) is also capable of potentiating LH-

*Correspondence.

Received 13 October 1997. induced androgen production by the thecal interstitial cells of the ovary (Cara and Rosenfield, 1988). The aim of the present study was to evaluate the role of insulin in stimulating high ovarian androstenedione production in S. heathi during the period of delayed ovulation.

\section{Materials and Methods}

Bats were captured live every 1-4 weeks from Banaras Hindu University campus and adjacent areas. The body weight of each bat was recorded. Bats were killed by decapitation as soon as they were taken to the laboratory. Serum was collected from blood samples (pooled blood from two bats) within $1 \mathrm{~h}$ and stored at $-20^{\circ} \mathrm{C}$ until assayed for insulin and androstenedione.

Scotophilus heathi has a sharply defined annual reproductive cycle (Abhilasha and Krishna, 1996) and can be classified into the following phases: (1) Quiescence: reproductively inactive phase; ovaries do not contain any antral follicles (August-September). (2) Recrudescence: beginning of reproductive activity; ovaries contain some newly formed antral follicles (October-November). (3) Winter dormancy (early phase of ovulatory delay): bats remain torpid showing temporary arrest in reproductive activity; ovaries contain some antral follicles (Decemberearly January). (4) Late phase of ovulatory delay: ovaries contain some antral follicles and mating occurs (midJanuary-mid-February). (5) Preovulatory period: renewed ovarian activity; ovaries contain large antral follicles (late February-early March). 


\section{In vitro study}

The in vitro study was performed to determine the effect of insulin on androstenedione production by $S$. heathi ovaries. The effect of insulin was compared with the effect of LH. The study was conducted during November because during this period the bats had very high serum concentrations of both insulin and androstenedione. As soon as the bats were taken to the laboratory the ovaries were dissected out and cleaned in media-199 (Gibco, Grand Island, NY). Ovaries (one per tube) were cultured for $2 \mathrm{~h}$ at $37^{\circ} \mathrm{C}$ in $1 \mathrm{ml}$ media- 199 containing $0.1 \%(\mathrm{w} / \mathrm{v}) \mathrm{BSA}$, different concentrations of human insulin $(0.4,1.0,2.0 \mathrm{iu})$ (Torrent Pharmaceuticals Ltd, Copenhagen) and with or without hCG $(0.1 \mu \mathrm{g})$ (Sigma, St Louis, MO).

In addition, the seasonal changes in insulin-induced androstenedione production by the ovary were studied. Ovaries collected from bats at different reproductive stages (quiescence (September), recrudescence (November) and preovulatory (February)) were incubated for $2 \mathrm{~h}$ in media-199 with insulin (1 iu) and with or without hCG $(0.1 \mu \mathrm{g})$. Samples were stored at $-20^{\circ} \mathrm{C}$ until assayed for androstenedione.

\section{Hormone assays}

Androstenedione. Radioimmunoassay for androstenedione was performed in incubation media without extraction. All the samples were run in one assay. The antibody for androstenedione was obtained from Dr John Resko (Portland, Oregon). The method used was as described by Abhilasha and Krishna (1996).

Insulin. The circulating insulin concentration in the bats was measured using a radioimmunoassay kit (RIAK-1) obtained from Bhabha Atomic Research Centre (Bombay). Verification of the insulin assay for use in the bat was performed. Blood serum samples from several bats were pooled, serially diluted with assay buffer and tested against a standard curve. Dilutions of bat serum ran parallel to the standard curve indicating the suitability of this assay for use in S. heathi (Fig. 1). Duplicate $0.1 \mathrm{ml}$ serum samples were used for the assay. Assay buffer, $0.3 \mathrm{ml}$, and $0.1 \mathrm{ml}$ insulin antiserum (guinea pig anti-human) were added to $0.1 \mathrm{ml}$ serum. After mixing gently, all the tubes were incubated overnight at $4^{\circ} \mathrm{C}$. ${ }^{125}$ I-labelled insulin $(0.1 \mathrm{ml})$ were then added to all tubes. The tubes were mixed gently and incubated for $3 \mathrm{~h}$ at room temperature. 0.1 $\mathrm{ml}$ of a second antibody (anti-guinea pig $\mathrm{IgG}$ ) and $1.0 \mathrm{ml}$ polyethylene glycol solution were added to all tubes except in total counts. Ail the tubes were vortexed, kept at room temperature for $20 \mathrm{~min}$ and then centrifuged at $1500 \mathrm{~g}$ for 20 min. The supernatant was discarded without disturbing the precipitate. Average counts per minute (c.p.m.) were taken for all duplicate tubes in a Beckman gamma counter (Beckman, Geneva). Standards (7.5-200 นiu ml-1), zero standard and blank tubes were also processed with the samples. All the samples were run in one assay. The intra-assay coefficient of variation was less than $7.8 \%$.

\section{Measurement of glucose}

Glucose was measured using a quantitative colorimetric procedure for the serum samples used for the insulin assay

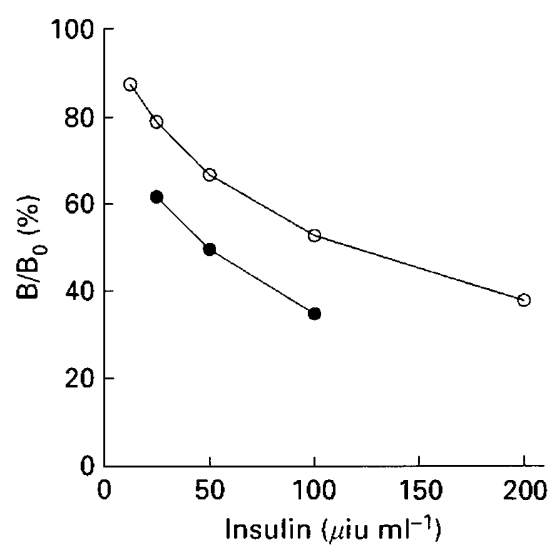

Fig. 1. Correlation between pooled blood serum samples from Scotophilus heathi $(\bullet)$ and a standard curve $(0)$. The coefficient of determination $\left(r^{2}\right)$ for the bat serum samples versus the standard curve $\left(\mathrm{B} / \mathrm{B}_{0}\right)$ was 0.97 .

using a kit from Stanbio (San Antonio, TX). The inter-assay precision of the assay was below $5 \%$.

\section{Binding of ${ }^{125}$ I-labelled insulin to ovarian sections}

The binding of ${ }^{125} \mathrm{I}$-labelled insulin to ovarian sections was studied using an autoradiographic method described previously (Bortolussi et al., 1979; Oxberry and Greenwald, 1982). Ovaries ( $n=3$ ) collected during November were used for autoradiography to localize insulin binding sites in the ovary. Iodinated insulin (specific activity $100 \mu \mathrm{Ci}_{\mu g^{-1}}$ insulin) was obtained from Bhabha Atomic Research Centre, Bombay. Bats were killed by decapitation and ovaries were removed, frozen immediately and sectioned at $10 \mu \mathrm{m}$ in a cryostat at $-20^{\circ} \mathrm{C}$. After fixation for $10 \mathrm{~min}$ in cold picric acidformaldehyde and subsequent washing in cold $0.01 \mathrm{~mol} \mathrm{PBS}{ }^{-1}$ ( $\mathrm{pH} 7.2$ ), sections were incubated for $2 \mathrm{~h}$ at $37^{\circ} \mathrm{C}$ with $25 \mu \mathrm{l}$ ${ }^{125}$ I-labelled human insulin (approximately 10000 c.p.m.) in PBS containing $0.1 \%$ BSA or $0.1 \%$ BSA with an excess of unlabelled human insulin. After incubation, the sections were washed in PBS, post-fixed in $4 \%$ paraformaldehyde-PBS, washed again in PBS and air dried. The sections were then coated with undiluted Kodak NTB-2, developed in Dektol (Kodak, Rochester, NY) and stained with nuclear red fast stain.

\section{Statistical analyses}

The data were analysed by one-way analysis of variance (ANOVA) followed by Duncan's multiple-range test. Correlation coefficient was used to compare the data. Data are expressed as means \pm SEM.

\section{Results}

\section{Serum glucose and insulin concentrations and insulin correlation with androstenedione}

Serum insulin concentration in female bats varied significantly during different reproductive stages $(P<0.05$, 


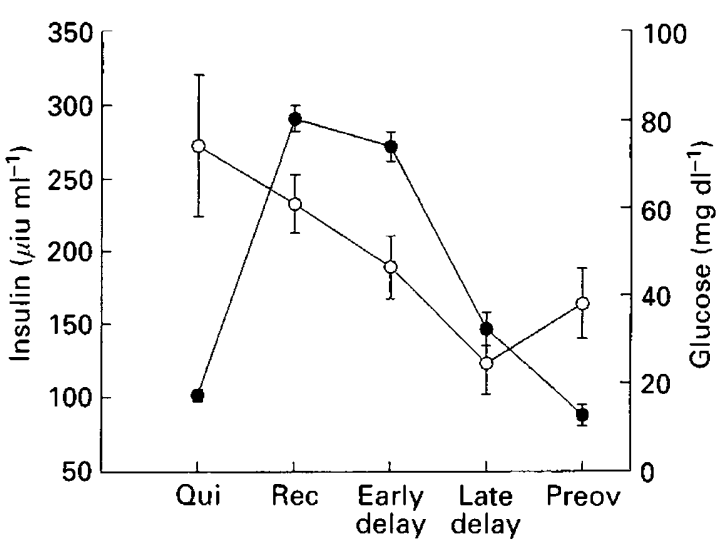

Reproductive phases

Fig. 2. Circulating glucose $(O)$ and insulin $(\bullet)$ concentrations in Scotophilus heathi during different reproductive phases. Qui, quiescence; Rec, recrudescence; Early delay, early phase of ovulatory delay; Late delay, late phase of ovulatory delay; Preov, preovulatory period. Values are means \pm SEM of five samples.

Fig. 2). Concentrations started to increase from August (quiescence), reached a peak during November (recrudescence) and remained high during December (winter dormancy). However, insulin concentrations declined sharply during February (breeding) and March (preovulatory). Serum glucose concentration in female bats also varied significantly during different reproductive stages $(P<0.05$, Fig. 2). Glucose concentrations were highest during quiescence, remained high during recrudescence and declined during December (winter dormancy) and February (late delayed period), but increased again during March (preovulatory). Serum insulin concentration showed a positive correlation with changes in body weight $(P<0.05$, Fig. 3). Serum insulin concentrations higher than $200 \mu$ iu $\mathrm{ml}^{-1}$ also showed a significant correlation $(P<0.05)$ with serum androstenedione concentration (Fig. 3), whereas insulin concentrations lower than $200 \mu \mathrm{iu} \mathrm{ml}^{-1}$ did not show significant correlation $(P>0.05)$. Abhilasha and Krishna (1996) described changes in serum androstenedione concentration during different reproductive stages in detail.

\section{Binding of ${ }^{125}$ I-labelled insulin to ovarian sections}

Autoradiographic results are shown in Fig. $4 a$ and b. The uptake of ${ }^{125} \mathrm{I}$ was mainly localized in the thecal cells and stromal or interstitial cells. The highest concentration of uptake was found in the thecal cells. There was only mild or non-specific binding to the granulosa cell layer. Specific uptake of ${ }^{125}$ I-labelled insulin was not detected in the control sections.

\section{Effect of insulin on ovarian androstenedione synthesis in vitro}

hCG increased ovarian production of androstenedione in vitro during November. Insulin also significantly increased

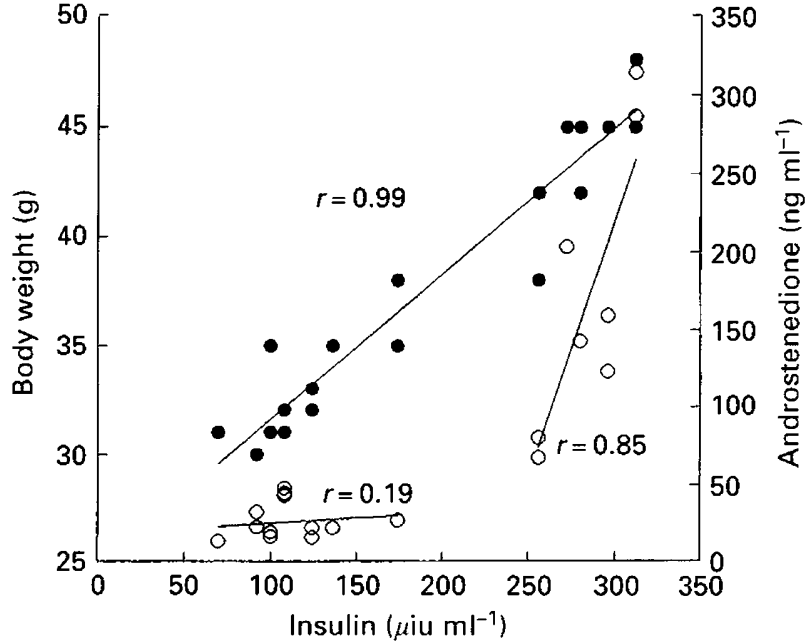

Fig. 3. Correlation between circulating insulin concentration and body weight $(\bullet)$ and circulating androstenedione concentration $(0)$ in Scotophilus heathi.

ovarian production of androstenedione in a dose-dependent manner. However, small doses of insulin did not augment hCG-induced androstenedione production (Table 1). Higher doses (2 iu) of insulin significantly enhanced hCG-induced androstenedione production compared with treatment with hCG (Table 1).

The effect of insulin on ovarian androstenedione production in vitro varied during different reproductive stages (Table 2). During recrudescence (November) 1 iu insulin was as effective as $0.1 \mu \mathrm{g} \mathrm{hCG}$ in stimulating ovarian androstenedione production. However, during quiescence (September) and the preovulatory period (February), insulin was significantly less effective than hCG in stimulating androstenedione production.

\section{Discussion}

An important finding of the present study is the statistical correlation between the seasonal changes of serum insulin and androstenedione concentrations in S. heathi. Both insulin and androstenedione concentration increased during the period of delayed ovulation and declined significantly during the preovulatory period. To our knowledge this is the first study to demonstrate a direct relationship between serum insulin and androstenedione concentration in any free living mammal, although such a relationship has been demonstrated in humans under pathological conditions such as PCOS, and in acanthosis nigricans (Burghen et al., 1980; Nagamani et al., 1986; Stuart et al., 1986; Conway et al., 1990).

Scotophilus heathi increases consumption of insects during the period from August to October in preparation for winter dormancy (Singh and Krishna, 1996). This period of increased insect consumption leads to extensive deposition of adipose tissue resulting in maximum body weight during November (Abhilasha and Krishna, 1997). Several studies have shown that circulating insulin concentration increases 

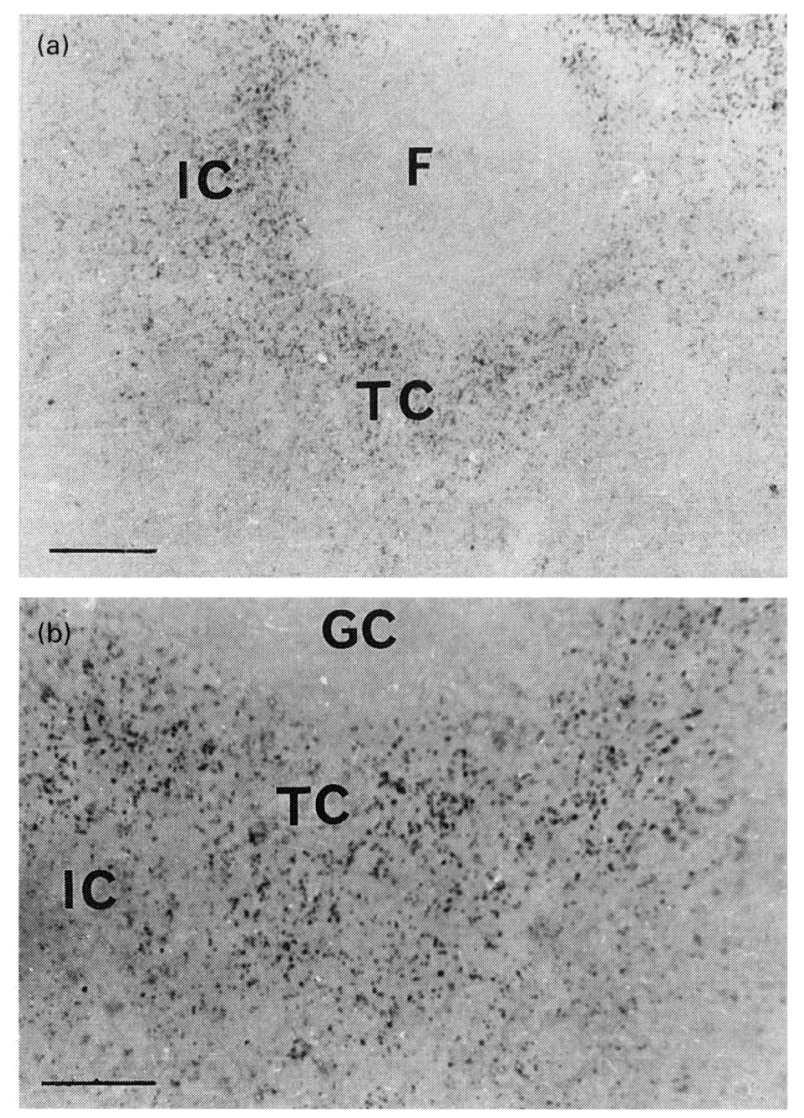

Fig. 4. (a) Autoradiographic localization of ${ }^{125}$ I-labelled insulin uptake in ovarian sections of Scotophilus heathi taken during November. (b) A magnified section of (a) showing localization of ${ }^{125} \mathbf{I}-$ labelled insulin in the thecal and interstitial cells. F, follicle; TC, thecal cells; IC, interstitial cells; GC, granulosa cells. Scale bars represents (a) $150 \mu \mathrm{m}$ and (b) $40 \mu \mathrm{m}$.

during the period of fattening with the peak concentrations occurring at the time of the maximum body weight and fat content prior to hibernation (Florant et al., 1985; Feist et al., 1986; Boswell et al., 1994). The highest serum insulin concentration in $S$. heathi was also observed during November, the period of maximum body weight and fat content. Overfeeding-induced increases in serum insulin may facilitate the accumulation of fat in response to energy surfeit (Forbes et al., 1989). In addition, it has been shown that reduction in body weight in an obese subject leads to a decline in the rate of insulin secretion (Gumbiner et al., 1996). A similar decline in serum insulin concentration was observed in $S$. heathi during winter dormancy, when a decline in body weight occurred due to gradual depletion of body fat. The present study demonstrated a positive correlation between circulating insulin concentration and changes in body weight in $S$. heathi.

Although hyperinsulinaemia and hyperandrogenism are normally positively correlated, the mechanisms linking these factors are still not clear. It was hypothesized that hyperandrogenism could be a primary event inducing hyperinsulinaemia (Burghen et al., 1980; Chang et al., 1983). However, chronic treatment with androgen does not alter insulin secretion (Lanzone et al., 1990). Other studies have suggested that hyperinsulinaemia is partly responsible for excessive androgen production (Poretsky, 1991; Nestler and Jakubowicz, 1996). Several studies in vitro on ovarian tissues from both animals and humans support this hypothesis (Barbieri et al., 1986; Morley et al., 1989). Exposure of S. heathi ovaries in vitro to a supraphysiological dose of human insulin during November significantly augmented the production of androstenedione. During this period, a supraphysiological dose of human insulin also significantly potentiated hCG-induced androstenedione production by the ovary. These findings support the hypothesis that insulin amplifies the LH-dependent mechanism that regulates ovarian androgen secretions (Barbieri et al., 1984; Hernandez et al., 1988).

The possibility of insulin exerting a direct stimulatory effect on ovarian androgen biosynthesis has previously been investigated (Barbieri et al., 1984). Demonstration of insulin binding sites in the ovary of $S$. heathi suggests direct action of insulin on the ovarian tissues. Although the nature of the binding site (receptor) in the present study remains to be determined, it is possible that our results are due to the interaction of high concentrations of insulin with IGF-I receptors. The presence of insulin and IGF-I receptors have been demonstrated and characterized in the rat, pig and human ovary (Otani et al., 1985; Poretsky et al., 1985; Hernandez et al., 1988). Binding sites for ${ }^{125} \mathrm{I}$-labelled human insulin in the ovary of $S$. heathi were found mainly in the thecal and stromal cells. Insulin was shown to induce luteinization of ovarian stromal cells and convert them into steroidogenically active luteinized stromal cells (Nagamani et al., 1986). Increased lipid droplet accumulation was observed in granulosa cell cultures treated with insulin (Channing et al., 1976). In women with PCOS insulin induces hyperthecosis in the ovary. Extensive stromal luteinization has also been shown in the ovary of $S$. heathi during November which coincides with a high concentration of circulating insulin (Abhilasha and Krishna, 1997). Indeed, virtually the entire interfollicular area of $S$. heathi ovaries were occupied by luteinized stromal cells during November (Abhilasha and Krishna, 1997). It is possible that the insulininduced increase in androstenedione synthesis may be partly mediated through stromal luteinization in S. heathi ovaries.

The present study showed seasonal variations in the effects of insulin on ovarian androstenedione production in vitro. Scotophilus heathi ovaries were found to be most responsive to insulin during recrudescence in November (Table 2), which also coincided with the peak in serum androstenedione concentration (Abhilasha and Krishna, 1996). In comparison, mild ovarian responsiveness to insulin was observed during August (quiescence) and February (preovulatory period). During these periods, S. heathi had low circulating androstenedione concentrations. The present study showed a threshold effect of circulating insulin on androstenedione concentration. The correlation between insulin concentrations lower than $200 \mu \mathrm{iu} \mathrm{ml} \mathrm{m}^{-1}$ and androstenedione was not significant, whereas a significant correlation was observed between insulin concentrations greater than $200 \mu \mathrm{iu} \mathrm{ml} \mathrm{m}^{-1}$ and androstenedione. This indicates that concentrations lower than $200 \mu \mathrm{iu} \mathrm{m} \mathrm{m}^{-1}$ had no 
Abhilasa and Krishna A (1997) Adiposity and androstenedione production in relation to delayed ovulation in the Indian bat, Scotophilus heathi. Comparative Biochemistry and Physiology 116C $97-101$

Barbieri RL, Makris A and Ryan RL (1984) Insulin stimulates androgen accumulation in incubations of human ovarian stroma and theca Obstetrics and Gynecology Supplement $6473 \mathrm{~s}-80 \mathrm{~s}$

Barbieri RL, Makris A, Randall RW, Daniels G, Kistner RW and Ryan KJ (1986) Insulin stimulates androgen accumulation in incubations of ovarian stroma obtained from women with hyperandrogenism Journal of Clinical Endocrinology and Metabolism 62 904-910

Barbieri RL, Smith S and Ryan KJ (1988) The role of hyperinsulinaemia in the pathogenesis of ovarian hyperandrogenism Fertility and Sterility 50 197-212

Bergh C, Carlsson B, Colsson JH, Selliskog U and Hillensjo T (1993) Regulation of androgen production in cultured human thecal cells by insulin-like growth factor and insulin Fertility and Sterility 59 323-331

Bortolussi M, Marini G and Reolon ML (1979) A histochemical study of the binding of ${ }^{125}$-hCG to the rat ovary throughout the estrous cycle Cell and Tissue Research 197 213-226

Boswell T, Woods SC and Kenagy GJ (1994) Seasonal changes in body mass, insulin and glucocorticoids of free living golden-mantled ground squirrels General and Comparative Endocrinology 96 339-346

Burghen GA, Givens JR and Kitobchi AE (1980) Correlation of hyperandrogenism with hyperinsulinism in polycystic ovarian disease Journal of Clinical Endocrinology and Metabolism 50 113-116

Cara JF and Rosenfield RL (1988) Insulin-like growth factor-I and insulin potentiate luteinizing hormone-induced androgen synthesis by rat ovarian thecal interstitial cells Endocrinology 123 733-739

Chang RJ, Nakamura RM, Judd HL and Kaplan SA (1983) Insulin resistance in non-obese patients with polycystic ovarian disease Journal of Clinical Endocrinology and Metabolism 57 356-359

Channing CP, Tsai V and Sacks D (1976) Role of insulin, thyroxin and cortisol in luteinization of porcine granulosa cells grown in chemically defined media Biology of Reproduction 15 235-247

Conway GS, Jocobs HS and Holly JMP (1990) Effects of luteinizing hormone, insulin, insulin-like growth factor-I and insulin-like growth factor binding protein-I in the polycystic ovarian syndrome Clinical Endocrinology 33 593-603

Evans DJ, Hoffmann RG, Kalkhoff RK and Kissebah AH (1984) Relationship of body fat topography to insulin sensitivity and metabolic profiles in premenopausal women Metabolism 33 68-75

Feist D, Florant G, Greenwood MRC and Feist C (1986) Regulation of energy stores in arctic ground squirrels: brown fat thermogenic capacity lipoprotein lipase and pancreatic hormones during fat deposition. In Living in the Cold: Physiological and Biochemical Adaptations pp 281-285 Eds HC Heller, XJ Musacchia, and LCH Wang. Elsevier, New York

Florant GL, Lawrence AK, Williams K and Bauman WA (1985) Seasonal changes in pancreatic $\beta$-cell function in euthermic yellow-bellied marmots American Journal of Physiology 249 R159-R165

Forbes GB, Brown MR, Welle SL and Underwood LE (1989) Hormonal response to overfeeding American Journal of Clinical Nutrition 49 608-611

Gumbiner B, Polonsky KS, Beltz WF, Griver K, Wallace P, Brechtel G and Henrey RR (1990) Effects of weight loss and reduced hyperglycemia on the kinetics of insulin secretion in obese non-insulin dependent diabetes mellitus Journal of Clinical Endocrinology and Metabolism 70 1594-1602
Guzick DS, Wing R, Smith D, Berga SL and Winters SJ (1994) Endocrine consequences of weight loss in obese, hyperandrogenic anovulatory women Fertility and Sterility 61 598-604

Hernandez ER, Resnick CE and Svoboda ME (1988) Somatomedin$\mathrm{C} /$ insulin-like growth factor-I as an enhancer of androgen biosynthesis by cultured rat ovarian cells Endocrinology 122 1603-1612

Krishna A and Singh UP (1992) Morphometric changes in the ovaries of Indian vespertilionid bat Scotophilus heathi with reference to delayed ovulation European Archives of Biology 103 257-264

Lanzone A, Fulgesu AM, Andreani CL, Apa R, Fortini A and Caruso A (1990) Insulin secretion in polycystic ovarian disease: effect of ovarian suppression by GnRH-agonist Human Reproduction 5 143-149

Morley P, Calaresu FR, Barbe GL and Armstrong DT (1989) Insulin enhances luteinizing hormone-stimulated steroidogenesis by porcine theca cells Biology of Reproduction 40 735-743

Nagamani N, VanDinh T and Kelver ME (1986) Hyperinsulinaemia in hyperthecosis of the ovaries American Journal of Obstetrics and Gynecology $154384-389$

Nestler JE and Jakubowicz DJ (1996) Decreases in ovarian cytochrome P450C $17 \alpha$ activity and serum free testosterone after reduction of insulin secretion in polycystic ovary syndrome New England lournal of Medicine 335 617-623

Nestler JE, Clore JN, Strauss JF and Blackard WG (1987) The effects of hyperinsulinaemia on serum testosterone, progesterone, dihydroepiandrosterone sulfate and cortisol levels in normal woman and in a woman with hyperandrogenism, insulin resistance and acanthosis nigricans Journal of Clinical Endocrinology and Metabolism 64 180-184

Otani T, Maruo T, Yukimura N and Mochizuki M (1985) Effect of insulin on porcine granulosa cells: implications of a possible receptor mediated action Acta Endocrinologica (Copenhagen) 108 104-110

Oxberry BA (1979) Female reproductive patterns in hibernating bats Journal of Reproduction and Fertility 56 359-367

Oxberry BA and Greenwald GS (1982) An autoradiographic study of the binding of ${ }^{125} \mathrm{I}$-labelled follicle stimulating hormone, human chorionic gonadotrophin and prolactin to the hamster ovary throughout the estrous cycle Biology of Reproduction 27 505-516

Polderman KH, Gooren LJG, Asscheman H, Bakker A and Heine RJ (1994) Induction of insulin resistance by androgens and estrogens Journal of Clinical Endocrinology and Metabolism 79 265-271

Poretsky L (1991) On the paradox of insulin induced hyperandrogenism in insulin-resistant states Endocrine Review 12 3-13

Poretsky L, Grigorescu F, Seibel M, Moses AC and Flier S (1985) Distribution and characterization of insulin and insulin-like growth factor-I receptors in normal human ovary Journal of Clinical Endocrinology and Metabolism 61 $728-734$

Singh K and Krishna A (1996) Seasonal changes in circulating serum concentration and in vitro testicular secretion of testosterone and androstenedione in the male vespertilionid bat (Scotophilus heathi) Journal of Experimental Zoology 276 43-52

Stuart CA, Peters EJ, Prince MJ, Richards G, Cavallo A and Meyer WJ (1986) Insulin resistance with acanthosis nigricans: the role of obesity and androgen excess Metabolism 35 197-205

Utiger RD (1996) Insulin and the polycystic ovary syndrome New England Journal of Medicine 335 657-658 